\title{
A microprocessor control system and solid state interface for controlling electrophysiological studies of conditioning
}

\author{
PAUL R. SOLOMON \\ Department of Psychology, Williams College, Williamstown, Massachusetts 01267 \\ DONALD J. WEISZ, GREGORY A. CLARK, and JOHN HALL \\ Department of Psychobiology, University of California, Irvine, California 92717 \\ and \\ BRYCE A. BABCOCK \\ Department of Physics, Williams College, Williamstown, Massachusetts 01267
}

\begin{abstract}
This paper describes a microprocessor control system and solid state interface for controlling the apparatus in combined behavioral-electrophysiological studies of conditioning. The computer program, which is designed to control classical conditioning of the rabbit's nictitating membrane response, provides the flexibility to control all conditioning parameters (e.g., interstimulus and intertrial intervals, trial type, and sequence of trial types) with only minor modifications. The system is free from artifacts that can distort electrophysiological recordings and can easily be modified to accommodate other behavioral paradigms in which electrophysiological responses are recorded.
\end{abstract}

Electrophysiological recording of neural activity from awake, behaving animals has become a widely used method for investigation of physiological bases of behavior. We have designed a programmable, computercontrolled system, with a solid state interface to the experimental apparatus, for conducting behavioral studies that involve recording of electrophysiological activity. The system is flexible, inexpensive, and free from electrical artifacts that can distort electrophysiological recordings. Although our system is designed for electrophysiological studies of rabbit neural activity during classical conditioning of the nictitating membrane response (NMR), other behavioral paradigms can easily be accommodated.

\section{THE PARADIGM}

The paradigm for classical conditioning of the rabbit NMR is a modification of that initially described by Gormezano (1966). In our paradigm, the conditioned stimulus (CS) has a duration of $350 \mathrm{msec}$, the uncondi-

Parts of this work were supported by NIMH Research Service Award Fellowships to Paul R. Solomon (MH0810501) and Donald J. Weisz (NS0564-03) and NSF Grant BNS76-17370-04 to Richard F. Thompson. We are grateful to Dr. Thompson for his help throughout the project. Donald J. Weisz is now at the Department of Psychology, Yale University, and Gregory Clark is now at the Department of Psychology, Stanford University.
Table 1

Timing Sequence for Variable ITI During Paired Training

\begin{tabular}{ccccc}
\hline $\begin{array}{c}\text { Memory } \\
\text { Location }\end{array}$ & $\begin{array}{c}\text { Memory } \\
\text { Contents }\end{array}$ & $\begin{array}{c}\text { Number } \\
\text { of Cycles }\end{array}$ & Time & $\begin{array}{c}\text { Total } \\
\text { ITI }\end{array}$ \\
\hline 0310 & B0 & 176 & 46 & 50 \\
0311 & FD & 253 & 66 & 70 \\
0312 & CB & 203 & 53 & 57 \\
0313 & F5 & 245 & 64 & 68 \\
0314 & DE & 222 & 58 & 62 \\
0315 & CF & 207 & 54 & 58 \\
0316 & EA & 234 & 61 & 65 \\
0317 & DA & 218 & 57 & 61 \\
0318 & B8 & 184 & 48 & 52 \\
\hline
\end{tabular}

Note-Time $=$ time (in seconds) from previous trial offset to given trial onset, determined by memory contents. Total $I T I=$ time (in seconds) from previous trial onset to given trial onset (i.e., includes $3.7 \mathrm{sec}$ of within-trial time). Mean $I T I=60 \mathrm{sec}$ (range $=50-70 \mathrm{sec}) ; l$ cycle $=260.1 \mathrm{msec}$.

tioned stimulus (UCS) has a duration of $100 \mathrm{msec}$, and the interstimulus interval (ISI) is $250 \mathrm{msec}$. The intertrial interval (ITI) ranges between 50 and $70 \mathrm{sec}$, with a mean of $60 \mathrm{sec}$ (Table 1). A typical conditioning session consists of 117 such trials divided into 13 blocks of 9 trials each. The first trial in each block is a CS-alone probe trial, and the remaining eight trials are composed of CS-UCS pairings.

As a control procedure for the electrophysiological studies, an explicitly unpaired program (see Rescorla, 
Table 2

Timing Sequence for Variable ITI During Unpaired Training

\begin{tabular}{|c|c|c|c|c|}
\hline $\begin{array}{l}\text { Memory } \\
\text { Location }\end{array}$ & $\begin{array}{l}\text { Memory } \\
\text { Contents }\end{array}$ & $\begin{array}{l}\text { Number } \\
\text { of Cycles }\end{array}$ & Time & $\begin{array}{l}\text { Total } \\
\text { ITI }\end{array}$ \\
\hline 0320 & $4 \mathrm{D}$ & 77 & 20 & 24 \\
\hline 0321 & $8 \mathrm{~A}$ & 138 & 36 & 40 \\
\hline 0322 & 50 & 80 & 21 & 25 \\
\hline 0323 & 73 & 115 & 30 & 34 \\
\hline 0324 & 45 & 69 & 18 & 22 \\
\hline 0325 & 67 & 103 & 27 & 50 \\
\hline 0326 & 77 & 119 & 31 & 35 \\
\hline 0327 & $7 \mathrm{E}$ & 126 & 33 & 37 \\
\hline 0328 & $6 B$ & 107 & 28 & 32 \\
\hline 0329 & $6 \mathrm{~B}$ & 107 & 28 & 32 \\
\hline $032 \mathrm{~A}$ & $3 \mathrm{D}$ & 61 & 16 & 20 \\
\hline $032 \mathrm{~B}$ & $7 \mathrm{E}$ & 126 & 33 & 37 \\
\hline $032 \mathrm{C}$ & 58 & 88 & 23 & 27 \\
\hline $032 \mathrm{D}$ & 86 & 134 & 35 & 39 \\
\hline $032 \mathrm{E}$ & 64 & 100 & 26 & 30 \\
\hline $032 F$ & 54 & 84 & 22 & 26 \\
\hline 0330 & 86 & 134 & 35 & 28 \\
\hline 0331 & 49 & 73 & 19 & 40 \\
\hline 0332 & 50 & 80 & 21 & 22 \\
\hline 0333 & $6 \mathrm{~B}$ & 107 & 28 & 25 \\
\hline 0334 & $6 \mathrm{~F}$ & 111 & 29 & 33 \\
\hline 0335 & $5 \mathrm{C}$ & 92 & 24 & 28 \\
\hline 0336 & $8 \mathrm{~A}$ & 38 & 36 & 40 \\
\hline 0337 & 49 & 73 & 19 & 23 \\
\hline 0338 & 73 & 115 & 30 & 34 \\
\hline 0339 & G4 & 100 & 26 & 30 \\
\hline $033 \mathrm{~A}$ & 45 & 69 & 18 & 22 \\
\hline $033 \mathrm{~B}$ & $6 \mathrm{~F}$ & 111 & 29 & 33 \\
\hline $033 \mathrm{C}$ & $7 \mathrm{E}$ & 126 & 33 & 37 \\
\hline 033D & 41 & 65 & 17 & 21 \\
\hline $033 \mathrm{E}$ & 64 & 100 & 26 & 30 \\
\hline $033 \mathrm{~F}$ & $6 \mathrm{~F}$ & 111 & 29 & 33 \\
\hline
\end{tabular}

Note-Time $=$ time (in seconds) from previous trial offset to given trial onset, determined by memory contents. Total ITI = time (in seconds) from previous trial onset to given trial onset (i.e., includes $3.7 \mathrm{sec}$ of within-trial time). Mean ITI $=30 \mathrm{sec}$ (range $=20-40 \mathrm{sec}) ; 1$ cycle $=260.1 \mathrm{msec}$. Memory contents are in hexadecimal (Base 16) in this and all subsequent tables.

1967) is used. In this paradigm, either the CS or the UCS is presented on a particular trial, but the two stimuli are never paired. The unpaired paradigm is run in blocks of 32 trials in which the CS and UCS are presented equal numbers of times in an unsystematic order. A conditioning session consists of 6.5 such blocks, for a total of 208 trials. The intertrial interval ranges from 20 to $40 \mathrm{sec}$, with a mean of $30 \mathrm{sec}$ (Table 2).

\section{THE KIM-1}

The KIM microcomputer is a single-board microcomputer marketed by MOS Technology (division of Commodore Business Machines). ${ }^{1}$ The KIM is based on the 6502 microprocessor and has been used in a variety of situations both to control the delivery of stimuli and to aid in data collection (Criswell \& Babcock, 1978; Murray \& Lawler, 1978; Parks, 1978). It has a calculatortype keypad for operator input with a six-digit LED display for output. A compact but versatile operating system resides in $2 \mathrm{~KB}$ of read-only memory (ROM) contained on two 6530 peripheral interface/memory devices. These also contain two user-accessible interval timers and 15 programmable input/output lines for external sensing and control. Random-access memory (RAM) of $1 \mathrm{~KB}$ is available on board for program and data storage. There are hardware routines for cassette tape data storage and retrieval and operation from an external terminal. Although the present program was developed for use with the KIM-1, it is easily adaptable to other microprocessors (e.g., the SYM-1 by Synertek and the Rockwell AlM-65).

\section{THE PROGRAM}

A computer program for classical conditioning of the rabbit's NMR must be capable of controlling a variety of events. In addition to controlling the delivery of the conditioned and unconditioned stimuli, the program must operate a polygraph and a tape recorder that are used for collecting and analyzing the electrophysiological and behavioral data. The program must also deliver a series of three synchronizing pulses that serve as event markers. The first pulse occurs $250 \mathrm{msec}$ prior to the CS onset and denotes the pre-CS period, which is used to sample baseline neural activity. The last two pulses coincide with delivery of the CS and the UCS. The pulses are used for subsequent computer analysis of the data (see Roemer, Cegavske, Thompson, \& Patterson, 1975).

The present program (Figure 1, Table 3 ) is an expanded version of that reported by Solomon and Babcock

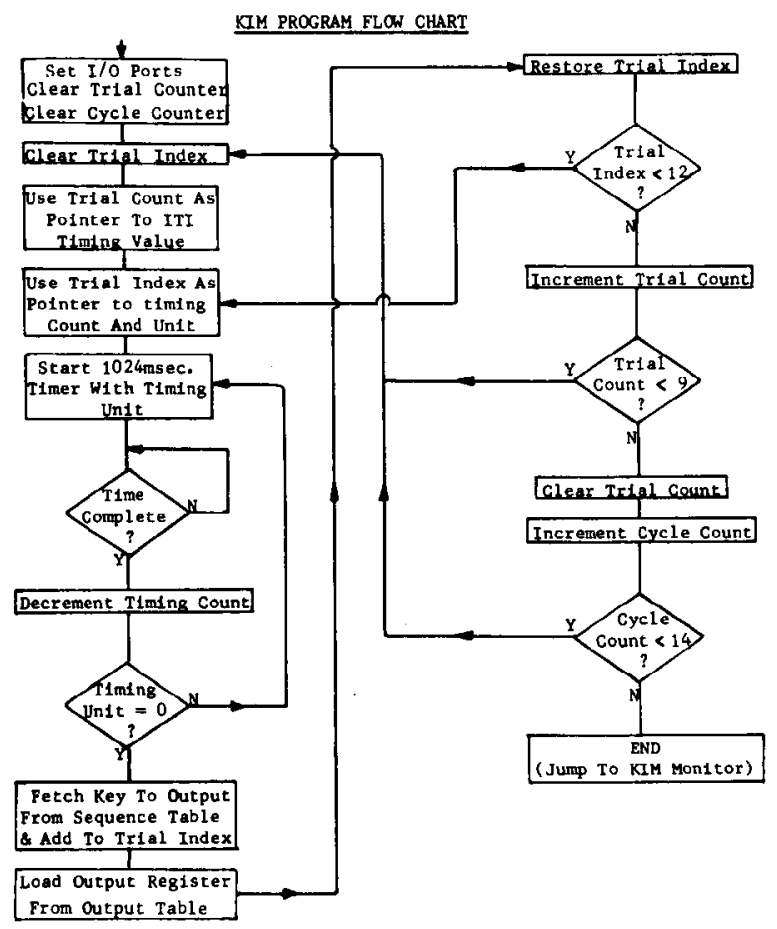

Figure 1. KIM program flowchart. 
Table 3

KIM NMR Conditioning Routine

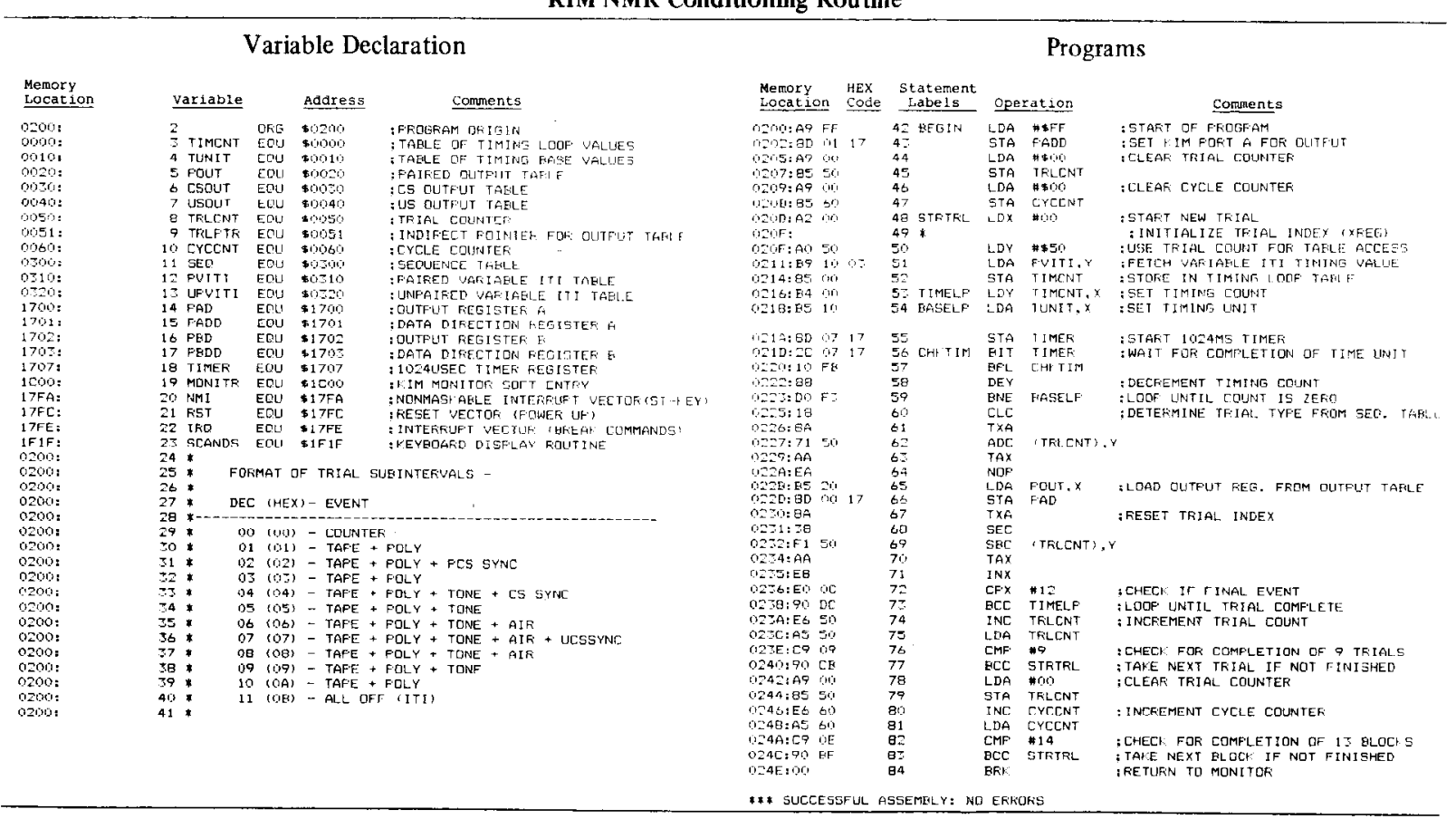

Note-Address 0051 (under "Variable Declaration") must be set to 03, the page number of the output tasks.

Table 4

Within-Trial Timing Values

\begin{tabular}{|c|c|c|c|c|c|c|c|}
\hline $\begin{array}{l}\text { Memory } \\
\text { Location }\end{array}$ & $\begin{array}{c}\text { Memory } \\
\text { Contents }\end{array}$ & Event & $\begin{array}{c}\text { Number } \\
\text { of Cycles }\end{array}$ & $\begin{array}{c}\text { Event } \\
\text { Duration }\end{array}$ & $\begin{array}{l}\text { Event } \\
\text { Onset }\end{array}$ & K Value & $\begin{array}{c}\text { Cycle } \\
\text { Duration }\end{array}$ \\
\hline \multicolumn{8}{|c|}{ Number of Cycles (Stored in Y Register) } \\
\hline 0000 & $*$ & ITI & $\dagger$ & $\dagger$ & 2607 & & \\
\hline 0001 & 62 & Counter & 98 & 100 & & & \\
\hline 0002 & $0 \mathrm{~A}$ & Tape + Polygraph & 10 & 1003 & & & \\
\hline 0003 & 01 & Tape + Polygraph + Tone + Pre-CS SP & 1 & 1 & 0 & & \\
\hline 0004 & $\mathrm{~F} 2$ & Tape + Polygraph & 242 & 248 & 1 & & \\
\hline 0005 & 01 & Tape + Polygraph + Tone + CS SP & 1 & 1 & 249 & & \\
\hline 0006 & D3 & Tape + Polygraph + Tone & 211 & 216 & 250 & & \\
\hline 0007 & $1 F$ & Tape + Polygraph + Tone + Air & 31 & 32 & 466 & & \\
\hline 0008 & 01 & Tape + Polygraph + Tone + Air + UCS SP & 1 & 1 & 498 & & \\
\hline 0009 & 43 & Tape + Polygraph + Tone & 67 & 69 & 499 & & \\
\hline $000 \mathrm{~A}$ & 20 & Tape + Polygraph + Tone & 32 & 33 & 567 & & \\
\hline $000 \mathrm{~B}$ & 14 & Tape + Polygraph & 20 & 2007 & 2574 & & \\
\hline \multicolumn{8}{|c|}{ Length of Each Cycle } \\
\hline 0010 & FE & ITI & & & & 254 & 260.1 \\
\hline 0011 & 01 & Counter & & & & 1 & 1.024 \\
\hline 0012 & 62 & Tape + Polygraph & & & & 98 & 100.4 \\
\hline 0013 & 01 & Tape + Polygraph + Pre-CS SP & & & & 1 & 1.024 \\
\hline 0014 & 01 & Tape + Polygraph & & & & 1 & 1.024 \\
\hline 0015 & 01 & Tape + Polygraph + Tone + CS SP & & & & 1 & 1.024 \\
\hline 0016 & 01 & Tape + Polygraph + Tone & & & & 1 & 1.024 \\
\hline 0017 & 01 & Tape + Polygraph + Tone + Air & & & & 1 & 1.024 \\
\hline 0018 & 01 & Tape + Polygraph + Tone + Air + UCS SP & & & & 1 & 1.024 \\
\hline 0019 & 01 & Tape + Polygraph + Tone & & & & 1 & 1.024 \\
\hline $001 \mathrm{~A}$ & 01 & Tape + Polygraph + Tone & & & & 1 & 1.024 \\
\hline $001 \mathrm{~B}$ & 62 & Tape + Polygraph & & & & 98 & 1.024 \\
\hline
\end{tabular}

Note-The total duration of an event is actually determined by two variables: the cycle duration and the number of cycles. The cycle duration is determined by the $K$ value, ranging from 1 to $254(1.024 .260 .1$ msec). The number of cycles (1-254) multiplied by the cycle duration then determines the total duration of the event $11.024 \mathrm{msec}$ to $66.1 \mathrm{sec})$. Event and cycle durations are given in milliseconds. "Event onset" = the number of milliseconds after the pre-CS synch pulse; SP = synch pulse.

*Loop in program. TVariable. 
(1979), modified to include an explicitly unpaired conditioning procedure, as well as the additional timing events. The program times 12 separate events ranging in duration from $1 \mathrm{msec}$ to $66 \mathrm{sec}$. At the conclusion of each timing interval, the KIM initiates an event. This is accomplished through the 15 input/output ports of the KIM board.

Three major types of variables are controlled by the KIM program: (1) timing value, the time for events within a trial (Table 4) or the time between trials (Table 1, paired program; Table 2, unpaired program); (2) the output command, which controls which events (e.g., CS delivery, UCS delivery, or both) occur on a particular type of trial (see Tables 5 and 6); and (3) the trial sequence, the choice of which type of trial (e.g., CS. alone, UCS-alone, or CS-UCS paired trial) will occur in the program sequence (Table 7, paired program; Table 8, unpaired program). Any of these variables can easily be changed by altering the contents of the relevant memory locations, allowing maximal flexibility.

\section{Timing Values}

The timing tables control the time between events such as tape recorder onset or stimulus delivery. During each trial, the program steps through 12 timing sequences (see Table 4 and Figure 1). The value for each of these times is stored in KIM memory in a timing table (Table 4 for within-trial values and Tables 1 and 2 for variable ITIs). In this way, the length of any event can be changed without affecting the remainder of the program by changing the contents of one memory location.

The timing values chosen for several events deserve special mention. First, the final stage of analysis on a PDP-12/PDP-11 computer system (Roemer et al., 1975) uses $3-\mathrm{msec}$ time bins; therefore, we have chosen the onset (or offset) of the stimulus events to coincide with the onset (or offset) of 3-msec intervals. For example, the pre-CS to CS interval is $249 \mathrm{msec}$ (not $250 \mathrm{msec}$ ).

A second point concerns the values chosen for the ITIs (Tables 1 and 2). We wish to set the interval from trial onset to next trial onset; however, the KIM times the interval between trial offset to next trial onset (i.e., it does not include the $3.7 \mathrm{sec}$ of within-trial time). Accordingly, the KIM values are approximately $4 \mathrm{sec}$ shorter than the desired ITIs (see Table 1).
Table 5

Output Commands for Paired, CS-Alone, and UCS-Alone Trials

\begin{tabular}{|c|c|c|}
\hline ML & $\mathrm{MC}$ & Event \\
\hline \multicolumn{3}{|r|}{ Paired Trials } \\
\hline 0020 & 04 & Counter \\
\hline 0021 & 08 & Tape + Polygraph \\
\hline 0022 & 28 & Tape + Polygraph + Pre-CS SP \\
\hline 0023 & 08 & Tape + Polygraph \\
\hline 0024 & $4 \mathrm{~A}$ & Tape + Polygraph + Tone + CS SP \\
\hline 0025 & $0 \mathrm{~A}$ & Tape + Polygraph + Tone \\
\hline 0026 & $1 \mathrm{~A}$ & Tape + Polygraph + Tone + Air \\
\hline 0027 & $9 A$ & Tape + Polygraph + Tone + Air + UCS SP \\
\hline 0028 & $1 \mathrm{~A}$ & Tape + Polygraph + Tone + Air \\
\hline 0029 & $\mathbf{0 A}$ & Tape + Polygraph + Tone \\
\hline $002 \mathrm{~A}$ & 08 & Tape + Polygraph \\
\hline 002B & 00 & All Off (ITI) \\
\hline \multicolumn{3}{|r|}{ CS-Alone Trials } \\
\hline 0030 & 04 & Counter \\
\hline 0031 & 08 & Tape + Polygraph \\
\hline 0032 & 28 & Tape + Polygraph + Pre-CS SP \\
\hline 0033 & 08 & Tape + Polygraph \\
\hline 0034 & $4 \mathrm{~A}$ & Tape + Polygraph + Tone + CS SP \\
\hline 0035 & $0 \mathrm{~A}$ & Tape + Polygraph + Tone \\
\hline 0036 & $0 \mathrm{~A}$ & Tape + Polygraph + Tone \\
\hline 0037 & $0 \mathrm{~A}$ & Tape + Polygraph + Tone \\
\hline 0038 & $\mathbf{0 A}$ & Tape + Polygraph + Tone \\
\hline 0039 & $0 \mathbf{A}$ & Tape + Polygraph + Tone \\
\hline $003 \mathrm{~A}$ & 08 & Tape + Polygraph \\
\hline $003 \mathrm{~B}$ & 00 & All Off (ITI) \\
\hline \multicolumn{3}{|r|}{ UCS-Alone Trials } \\
\hline 0040 & 04 & Counter \\
\hline 0041 & 08 & Tape + Polygraph \\
\hline 0042 & 28 & Tape + Polygraph + Pre-CS SP \\
\hline 0043 & 08 & Tape + Polygraph \\
\hline 0044 & 08 & Tape + Polygraph \\
\hline 0045 & 08 & Tape + Polygaph \\
\hline 0046 & 18 & Tape + Polygraph + Air \\
\hline 0047 & 98 & Tape + Polygraph + Air + UCS SP \\
\hline 0048 & 18 & Tape + Polygaph + Air \\
\hline 0049 & 08 & Tape + Polygraph \\
\hline $004 \mathrm{~A}$ & 08 & Tape + Polygraph \\
\hline $004 \mathrm{~B}$ & 08 & All Off (ITI) \\
\hline
\end{tabular}

Note-The manner in which these output command tables determine which stimuli are delivered is as follows. At the end of a programmed timing sequence, the microprocessor goes to the corresponding memory location in the output table and moves the contents of this location to Output Port A. (Although the KIM has two 8-bit output ports, only one is needed for this particular program.) Each bit in the output port controls one piece of apparatus (e.g., counter, tone generator, etc.), as indicated in Table 6. $M L=$ memory location, $M C=$ memory contents, and SP $=$ synch pulse.

Table 6

Output Port A (Memory Location 1700)

\begin{tabular}{ccccccccccc}
$\begin{array}{c}\text { Memory } \\
\text { Location }\end{array}$ & $\begin{array}{c}\text { Memory } \\
\text { Contents }\end{array}$ & Event & UCS & CS & Pre-CS & Air & $\begin{array}{c}\text { Tape }+ \\
\text { Polygraph Counter }\end{array}$ Tone & Open \\
\hline 0020 & 04 & Counter & 0 & 0 & 0 & 0 & 0 & 1 & 0 \\
\hline
\end{tabular}

Note-A "I" in any location represents a 5.V output pulse that, through the interface, turns on the apparatus to which the bit is connected. For example, our trial counter is connected to the third output bit; an " 04 " in hexadecimal indicates that this bit is high $(+5 \mathrm{~V})$ and all others are low $(0 \mathrm{~V})$. Thus, at the end of the ITI timing sequence in the paired trial, the KIM-1 accesses Memory location 0020, moves the memory contents (04) to Output Port A (Memory Location 1700), and thereby turns on the counter. 
The final consideration concerns the time at which the airpuff solenoid is activated. To compensate for the extra time necessary for the compressed air to travel through the Tygon tubing from solenoid to cornea, the solenoid must be activated before the desired time of airpuff delivery (see Figure 2). The arrival of the airpuff (and hence, delay time) can be accurately measured by holding the end of the Tygon tube to an open lead of an amplifier or to a BNC terminal on a high-gain oscilloscope. In our apparatus, the delay from solenoid activation to airpuff arrival at cornea is approximately $32 \mathrm{msec}$. However, this value varies according to tubing length and must be empirically determined for each case.

\section{Output Commands}

At the conclusion of each timing loop, the program points to one of three tables that contain output commands (see Table 5). These tables determine the stimuli to be delivered on a given type of trial. In the paired paradigm, there are two output tables that can be accessed. The first contains output commands for paired CS-UCS trials, and the second contains commands for the CS-alone trials. The unpaired paradigm also makes use of the CS-alone output table, as well as a third output table that controls UCS-alone trials.

\section{Trial Sequence}

Finally, to determine the output table to be accessed, (i.e., which type of trial will occur), we use a trial sequence table for paired (Table 7) and unpaired (Table 8) paradigms. At the conclusion of each trial, the program points to one of the locations in the output sequence table. The contents of this location determines which of the three output tables (in Table 5) is accessed. In the present program, a 00 in any location will lead to

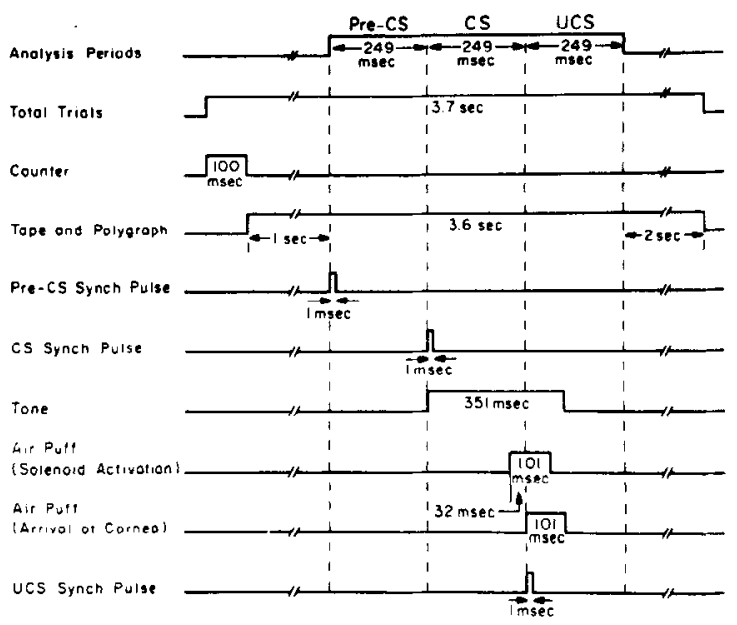

Figure 2. Timing values for each of the events in the conditioning paradigm.
Table 7

Trial Sequence for Paired Training

\begin{tabular}{cccc}
\hline $\begin{array}{c}\text { Memory } \\
\text { Location }\end{array}$ & $\begin{array}{c}\text { Memory } \\
\text { Contents }\end{array}$ & $\begin{array}{c}\text { Trial } \\
\text { Number }\end{array}$ & $\begin{array}{c}\text { Trial } \\
\text { Type }\end{array}$ \\
\hline 0300 & 10 & 1 & CS \\
0301 & 00 & 2 & P \\
0301 & 00 & 3 & $\mathbf{P}$ \\
0303 & 00 & 4 & $\mathbf{P}$ \\
0304 & 00 & 5 & $\mathbf{P}$ \\
0305 & 00 & 6 & $\mathbf{P}$ \\
0306 & 00 & 7 & $\mathrm{P}$ \\
0307 & 00 & 8 & $\mathbf{P}$ \\
0308 & 00 & 9 & $\mathbf{P}$ \\
\hline
\end{tabular}

Note-When computer points to Memory Location 0300, it adds the contents of this location to 0020 to determine the address of the first output command of the trial (Table 5). Thus, on paired trials, the output commands start at Memory Location 0020, on CS-alone trials at 0030, and on UCS-alone trials on 0040. By changing the contents of Memory Locations 0300-0308, any sequence of CS, UCS, and CS.UCS trials are possible, and by adding additional output tables, many different stimulus configurations are possible.

Table 8

Trial Sequence for Unpaired Training

\begin{tabular}{cccl}
\hline $\begin{array}{c}\text { Memory } \\
\text { Location }\end{array}$ & $\begin{array}{c}\text { Memory } \\
\text { Contents }\end{array}$ & $\begin{array}{c}\text { Trial } \\
\text { Number }\end{array}$ & $\begin{array}{l}\text { Trial } \\
\text { Type }\end{array}$ \\
\hline 0300 & 10 & 1 & CS \\
0301 & 20 & 2 & UCS \\
0302 & 10 & 3 & CS \\
0303 & 10 & 4 & CS \\
0304 & 20 & 5 & UCS \\
0305 & 10 & 6 & CS \\
0306 & 20 & 7 & UCS \\
0307 & 20 & 8 & UCS \\
0308 & 20 & 9 & UCS \\
0309 & 10 & 10 & CS \\
$030 \mathrm{~A}$ & 20 & 11 & UCS \\
$030 \mathrm{~B}$ & 10 & 12 & CS \\
$030 \mathrm{C}$ & 20 & 13 & UCS \\
$030 \mathrm{D}$ & 20 & 14 & UCS \\
$030 \mathrm{E}$ & 10 & 15 & CS \\
$030 \mathrm{~F}$ & 10 & 16 & CS \\
0310 & 20 & 17 & UCS \\
0311 & 10 & 18 & CS \\
0312 & 10 & 19 & CS \\
0313 & 20 & 20 & UCS \\
0314 & 20 & 21 & UCS \\
0315 & 10 & 22 & CS \\
0316 & 20 & 23 & UCS \\
0317 & 10 & 24 & CS \\
0318 & 10 & 25 & CS \\
0319 & 10 & 26 & CS \\
$131 \mathrm{~A}$ & 20 & 27 & UCS \\
$031 \mathrm{~B}$ & 10 & 28 & CS \\
$031 \mathrm{C}$ & 20 & 29 & UCS \\
$031 \mathrm{D}$ & 20 & 30 & UCS \\
$031 \mathrm{E}$ & 10 & 31 & CS \\
$031 \mathrm{~F}$ & 10 & 32 & UCS \\
\hline
\end{tabular}

a CS-UCS trial, a 10 will produce a CS-alone trial, and a 20 will produce a UCS-alone trial. At the end of nine trials, which constitutes a block in our paradigm, the paired program recycles to the beginning of the sequence. The unpaired program recycles after 32 trials. 
This system provides a high degree of flexibility. By altering the contents of the locations in the output sequence table and, if necessary, adding additional output tables, the user can obtain any combination of stimulus configurations within a block of trials. In addition, with minimal reprogramming (simply increasing the number of locations in the output sequence table), the user can change the number of trials and thus the possible stimulus configurations within a block of trials (e.g., for discrimination paradigms, see Solomon \& Babcock, 1979). For example, in the paired program, we use one CS-alone trial followed by eight paired trials, for a total of nine trials per block. In the unpaired program, however, we use an unsystematic sequence of $32 \mathrm{CS}$. alone or UCS-alone trials. To accomplish this, the number of memory locations in the trial sequence table is increased to 32 (by changing the contents of Memory Location 023F from 09 to 20; see Table 8).

\section{COMPATIBILITY WITH OTHER MICROPROCESSORS}

While the KIM has become a much used laboratory instrument, its features have been extended by second generation boards, particularly the SYM-1 by Synertek and the AIM- 65 by Rockwell. ${ }^{2}$ All the features of our present conditioning control system can be implemented easily with either the SYM or AIM microcomputers. Both of these boards contain significantly enhanced standard features when compared to the KIM while allowing for considerable on-board expansion (including a BASIC language interpreter, an assembler, and up to $4 \mathrm{~KB}$ of RAM). The more expensive AIM-65 comes with a typewriter-style keyboard and a 20-column printer. Both of the second-generation boards have attempted to maximize compatability with the existing KIM architecture. Software and hardware differences are generally noted in their literature, and suggestions are given for adapting KIM programs to their systems (see DeJong, 1980 , for a comparison of the KIM, SYM, and AIM microprocessors).

The major area of difference, apart from the more sophisticated operating systems, lies with input and output. The input/output devices are located at different addresses and are initialized in slightly different ways. The SYM and AIM use 6522 versatile interface adapters instead of the 6530 . Each 6522 has two interval timers, 16 input/output lines, and 4 "handshaking" lines. The interval timers are particularly powerful and can function as digital pulse generators and pulse counters.

The basic 6522 timer operation consists of presetting a 16-bit counter and decrementing it at the microprocessor clock rate until it reaches zero. The comparable KIM operation involves setting an 8-bit counter and decrementing it at the clock rate divided by $1,8,64$, or 1,024 . In the present system, the 1,024 rate provides a time scale in the $1-\mathrm{msec}$ range. This can easily be emu- lated on a SYM or AIM system by using the 6522 to time 1-msec intervals and adding an extra loop to the timing portion of the program to count these. The 6522 timers will run continuously at a preset rate, providing the equivalent of a real-time clock independent of program execution time. (The KIM timers must be reset by the program when they time out.)

of course, these are not the only single-board microcomputers available that are capable of controlling a typical conditioning system. Several other systems using alternative microprocessors $(1802,6800,8080, \mathrm{Z} 80$, etc.) are available. We have stressed the 6502 family of microcomputer boards because of their similarity to the present system and the ease with which this system could be adapted (DeJong, 1980).

Smaller, "dedicated," microcomputer boards such as the John Bell Engineering 6502 are also fully capable of such control systems if provided with the appropriate program in electrically programmable memory (EPROM). Such dedicated boards do not have operator input and output via keyboard and display. They are programmed to perform a preset series of operations. Since this is typical of a standard conditioning system, these boards can provide a significant cost reduction in the case of redundant setups. In addition, they provide easy on-off use, simplifying operator training. EPROM programmers are available for use with most microcomputers, as well as ultraviolet lamps for erasing EPROMS so that they may be reused. ${ }^{3}$

Scandrett and Gormezano (1980) report a system that uses an Apple II to control the conditioning paradigm and to also collect and analyze analog data from the NMR. We recently developed a combined KIM-1 and Apple II system that not only controls the conditioning paradigm and collects analog data from the NMR, but also collects electrophysiological data, plots poststimulus histograms, and computes standard scores (Solomon, Babcock, \& Gastell, Note 1). These Applebased systems have many advantages, but they tend to be comparatively expensive (between $\$ 4,000$ and $\$ 5,000$ for a complete setup). A microprocessor-based system is capable of performing the same control functions and can be fully configured for less than $\$ 500$.

\section{THE INTERFACE}

The interface between the KIM-1 and the experimental apparatus minimizes electrical artifacts in the neural recordings. Figure 3 depicts the primary components of the interface. At the first stage of the interface, each KIM 5.V output is buffered by feeding the $5-\mathrm{V}$ pulses into one gate of a Type 7406 TTL hex inverter driver. The outputs of the 7406 drivers switch the inputs of optical isolators (GE optical isolator Model H11B255).

Optoelectronic couplers provide an ideal means of isolating the computer and its associated power supplies from the physiological system under observation. This 
A

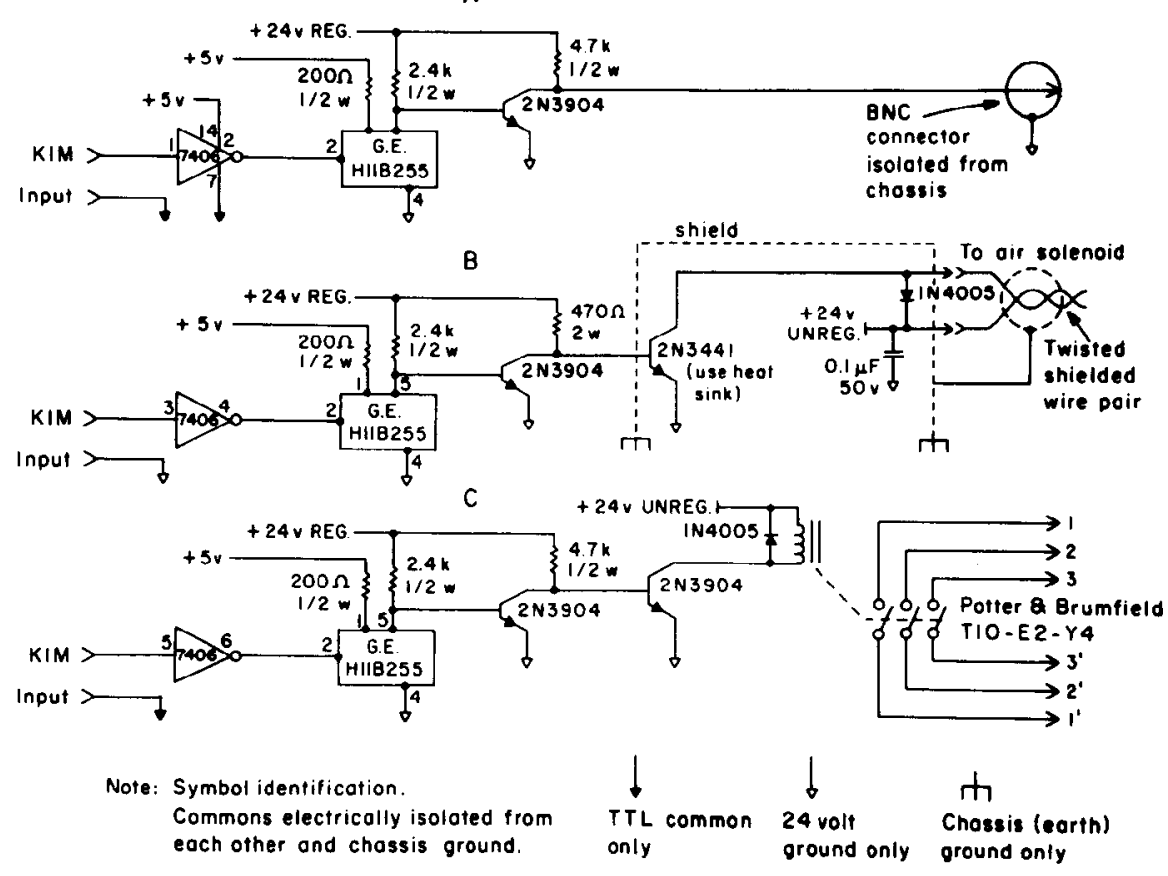

Figure 3. Schematic diagram of interface between KIM and conditioning apparatus.

helps to eliminate ground loop and noise problems in the electronic circuitry, as well as eliminating possible unknown and unwanted electrical stimuli to the subject. The only disadvantage of such isolation is the time delay that signals experience in passing through optocouplers. For the isolation unit used in the present setup, H1 1B255, the delays are of the order of 100 microsec. This provides no problems whatsoever for our conditioning system. In analyzing systems with significantly more rapid response, the $4 \mathrm{~N} 29-4 \mathrm{~N} 30$ series of optocouplers is more appropriate (delays less than $<50$ microsec). (Optocouplers are available with delays less than 100 nanosec. Hewlett-Packard's 6 N137 is such a device.)

The output of each optical isolator controls a transistor (2N3904). The type of connection made from the transistors depends on the characteristics of the electrical signals needed to operate various pieces of equipment. There are three possibilities. If the input to the piece of equipment is to the base of a transistor and the current is less than $200 \mathrm{~mA}$, then the output of the 2N3904 can be connected directly to the equipment (Figure 3A).

A different type of situation arises when the power requirements of the experimental apparatus are greater than the capabilities of the $2 \mathrm{~N} 3904$. If the apparatus requiring high power needs to be operated at a time when electrophysiological recordings are being made, we recommend that the $2 \mathrm{~N} 3904$ output be connected to the base of a power transistor (e.g., 2N344 1, Figure 3B). The power transistor should be attached to a heat sink and enclosed in a small chassis box. We recommend that a diode be used to minimize transients. The control circuitry for the air solenoid (Figure $3 \mathrm{~B}$ ) is an example of this type of system.

If the apparatus requiring high power is turned on and off at times when no important information is being recorded, relays can be used in place of the power transistors (Figure 3C). Multiple-pole relays can be used if two or more circuits are switched on and off simultaneously; for example, a tape recorder and a polygraph can be operated simultaneously by a multiple-pole relay. We chose to provide an additional stage of isolation when driving relays by adding a second 2N3904 transistor and a diode. Thus, relay switching transients are further buffered from the optical isolation. The relay may be simpler to use than the power transistor, since the relay circuit does not require a heat sink.

An example will serve to illustrate how this circuit operates. Entering a "04" in Memory Location 1700 activates the output bit devoted to the trial counter (see Table 6); when the output bit goes high ( $+5 \mathrm{~V}$ ), the 7406 driver goes low $(0 \mathrm{~V})$. This provides a "sink" for current through the LED in the optical isolator. This turns the LED on, which in turn activates the output phototransistor within the optical isolator. Since the phototransistor now conducts to ground, it robs the first 2 N3904 of its base current, and the 2N3904 turns off. This turns on the second 2 N3904. (Note that turning the transistor of one stage on turns the next transistor off, and vice versa.) Current can now flow through 


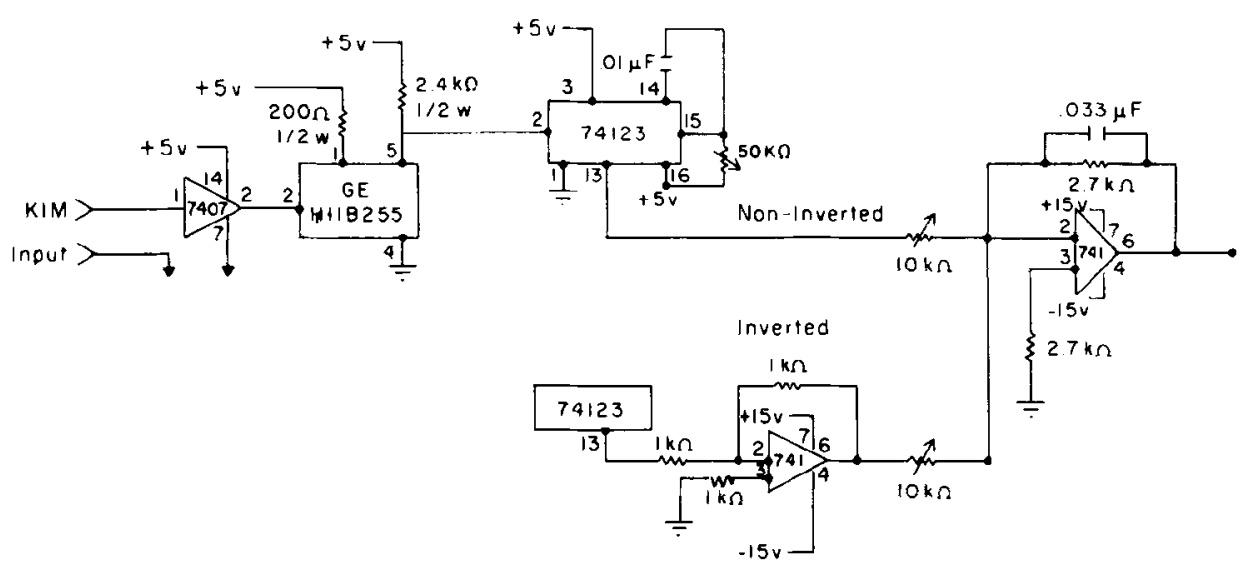

Figure 4. Schematic diagram for generating synchronous pulses.

the solenoid to ground via the transistor, and the counter is activated. The logic is simply reversed when the KIM output bit goes low.

In order to minimize electrical artifacts, close attention must be paid to the ground circuits. We use one ground circuit with the KIM inputs, a second with the optical isolators, transistors, and synchronizing pulse circuits, and a chassis (earth) ground.

Since we are interested in time-locked events, synchronizing pulses must be generated. These pulses are used to signal to the computer when key events occur. There are two major considerations in designing the synchronizing pulse circuit: (1) shaping the pulses to make them compatible with direct audio recording, and (2) having pulses of different polarities and/or amplitudes to allow discrimination between them.

The circuit shown in Figure 4 meets both of these requirements. Timing of synch pulse delivery per se is determined by the program. The KIM output $(5 \mathrm{~V}$, 1-msec duration) controls one gate of a 7407 driver, which in turn initiates an output from an optical isolator. At this point, the pulses are shortened and shaped to prevent overshoot (with most audio systems, dc components cannot be recorded, and a long monophasic pulse will be recorded as a biphasic one). The width of the pulse was first shortened from $1.0 \mathrm{msec}$ to approximately $.1 \mathrm{msec}$ using a dual monostable multivibrator (74123) as a simple timer. The inclusion of a potentiometer in the circuit allows greater flexibility in determining the width of the synch pulses. In addition, a capacitor is placed on the feedback of the summing circuit (described below) to shape pulse rise time, thereby eliminating the remaining $(.1-\mathrm{msec}) \mathrm{dc}$ component.

The 74123 outputs are then sent into an op-amp circuit, which sums them. By varying the polarity and amplitude of the pulses, each stimulus event generates its own unique synch pulse. The polarity of the UCS synch pulse is inverted by the first op-amp; the pre-CS and $\mathrm{CS}$ synch pulses bypass this stage, remaining positive. The second op-amp sums (and inverts) all three synch pulses. Amplitudes of the individual synch pulses can be varied by changing the input resistances. Using this circuit, three distinct synch pulses can be shaped: a negative pulse $(-1 \mathrm{~V})$, a large negative pulse $(-2 \mathrm{~V})$, and a large positive pulse $(+2 \mathrm{~V})$. The first signals trial onset, the second signals tone onset, and the third synch pulse signals delivery of the airpuff to the cornea. The output of the summing circuit can be sent directly to the tape recorder.

\section{REFERENCES}

Criswell, H. E., \& Babcock, B. A. A low-cost high-speed digital data acquisition and display system. Behavior Research Methods \& Instrumentation, 1978, 10, 476-479.

DeJono, M. L. Programming and interfacing the 6502 with experiments. Indianapolis: Sams, 1980.

Gormezano, 1. Classical conditioning. In J. B. Sidowski (Ed.), Experimental methods and instrumentation in psychology. New York: McOraw-Hill, 1966.

MuRRay, D. M., \& Lawler, J. E. A KIM-1 microprocessor interface for aversive conditioning applications using multiple sub. jects. Behavior Research Methods \& Instrumentation, 1978, 10, 334-339.

Parrs, E. R. A general-purpose microcomputer configuration for controlling experiments. Behavior Research Methods \& Instrumentation, 1978, 10, 480-484.

Rescorla, R. A. Pavlovian conditioning and its proper control procedures. Psychological Review, 1967, 74, 71-80.

Roemer, R. A., Cegavere, C. F., Thompson, R. F., \& PAtrerson, M. M. An acquisition and analysis system for online experiments on the neurophysiology of learning. Behavior Research Methods \& Instrumentation, 1975, 7, 157-161.

Scandrett, J., \& Gormezano, I. Microprocessor control and

\section{REFERENCE NOTE}

1. Solomon, P. R., Babcock, B. A., \& Gastell, D. A microcomputer (Apple II) -based system for acquisition and analysis of neurophysiological correlates of learning. Manuscript in preparation, 1983. 
A/D data acquisition in classical conditioning. Behavior Research Methods \& Instrumentation, 1980, 12, 120-125.

Solomon, P. R., \& BAвcock, R. A. KIM and the rabbit: The use of the KIM-1 microprocessor to control classical conditioning of the rabbit's nictitating membrane response. Behavior Research Methods \& Instrumentation, 1979, 11, 67-70.

\section{NOTES}

1. The KIM-1 and manuals are currently available from Falk-Baker Associates, 382 Franklin Avenue, Nutley, New Jersey 27110.
2. Synertek (Synertek Systems Corporation, P.O. Box 552, Santa Clara, California 95052) has recently announced a "SYM-2" board that is fully compatible with "SYM-1."

3. "Memory Plus" from Johnson Computer (P.O. Box 523, Medina, Ohio 44256) is a memory expansion board for the KIM, SYM, AIM family that has a built-in EPROM programmer. John Bell Engineering (P.O. Box 338. Department C881, Redwood City, California 94064) makes an EPROM programmer for the Apple computer.

(Received for publication May 28, 1982; revision accepted November 16,1982 .) 